\title{
Fast Assessment of Mineral Constituents in Grass by Inductively Coupled Plasma Optical Emission Spectrometry
}

\author{
Éder José dos Santos ${ }^{1}$, Loana Mara Baika ${ }^{1}$, Amanda Beatriz Herrmann ${ }^{1}$, Suzete Kulik ${ }^{1}$, \\ Charyane Satie Sato ${ }^{1}$, Arlene Bispo dos Santos ${ }^{1}$ and Adilson José Curtius ${ }^{2 *}$ \\ ${ }^{I}$ Instituto de Tecnologia do Paraná; C. P.: 357; 81310-020; Curitiba - PR - Brasil. ${ }^{2}$ Departamento de Química; \\ Universidade Federal de Santa Catarina; 880400-900; Florianópolis - SC - Brasil
}

\begin{abstract}
A method for evaluating inorganic constituents in the grass by ICP OES is proposed. The samples were digested with nitric acid plus hydrogen peroxide in a microwave system. Seventeen samples were collected in the metropolitan area of Curitiba and Castro in the Paraná State, Brazil. The following elements were studied: Al, As, $\mathrm{Ba}, \mathrm{Ca}, \mathrm{Cd}, \mathrm{Co}, \mathrm{Cr}, \mathrm{Cu}, \mathrm{Fe}, \mathrm{K}, \mathrm{Mg}, \mathrm{Mn}, \mathrm{Mo}, \mathrm{Na}, \mathrm{Ni}, \mathrm{P}, \mathrm{Pb}, \mathrm{Sb}$, Se and $\mathrm{Zn}$. The linear coefficients of the curves were higher than 0.999 and the precision, expressed as the relative standard deviation, which was below 10\%, being considered adequate. The accuracy was validated by using the recovery test (recoveries from 80 to $107 \%$ ) and by the analysis of botanical certified materials. For one sample, two other digestion procedures, using two different mixtures of nitric and hydrochloric acids, produced results in agreement with the adopted procedure. Eleven out of the twenty studied elements could be quantified in real samples. High concentrations of $\mathrm{Ca}, \mathrm{K}, \mathrm{Mg}$ and $\mathrm{P}$, the essential elements for bovines and other animals, were found. The results were evaluated using the principal component analysis that gathered the samples in three groups, according to the areas where the plants were grown.
\end{abstract}

Key words: ICP OES, Inorganic constituents, Acid digestion, PCA

\section{INTRODUCTION}

Grass plants are among the main fodder sources for bovines, being considered as a voluminous feed, growing rapidly in favorable conditions and presenting high contents of fibers and water. They also can provide the majority of the required nutrients, depending on the animal species, soil quality, plant fertility and age, among other factors. Efficient pasture management is required to guarantee the availability of the nutrients. Brazil has the biggest cattle herd in the world, with more than $95 \%$ of the animals being grown in pastures. Certainly, the milk and meet quality will depend on the grass composition, which should be known (Martuscelo et al. 2009; Souza et al. 2007).
For an adequate animal feed, inorganic nutrients or mineral compounds are required. Some of the nutrients are present in the grass as an inorganic salt, for example as $\mathrm{CaCO}_{3}$ or as part of an organic compound, for example P in caseine. Usually, the nutrients are classified as macro constituents, such as $\mathrm{Ca}, \mathrm{K}, \mathrm{Mg}, \mathrm{Na}$ and $\mathrm{P}$ and as micro constituents, such as $\mathrm{Cu}, \mathrm{Co}, \mathrm{Fe}, \mathrm{Mn}, \mathrm{Mo}$, Se and $\mathrm{Zn}$. The macro constituents are required in levels from $0.2 \%$ to $1 \%$ of the animal corporal mass, while the micro constituents are required from $0.001 \%$ to $0.05 \%$ of the corporal mass. Some of the mineral constituents are stored in the organism, such as $\mathrm{Fe}$ in the liver or $\mathrm{Ca}$ in the bones, while the nutrients that are readily soluble in water, such as $\mathrm{Na}$ and $\mathrm{K}$, are not stored and must be supplemented

\footnotetext{
*Author for correspondence: eder@ tecpar.br
} 
continuously by the food. However, deficiency or toxicity symptoms can be verified for low or high constituent concentration, respectively. Selenium, $\mathrm{Mo}$ and $\mathrm{Cu}$ toxicity can lead to problematic feeding situations. Elements such as $\mathrm{As}, \mathrm{Cd}$ and $\mathrm{Pb}$ can be present in the grass due to environmental pollution. The knowledge of the chemical composition of the grass certainly is very important for the producer and also for the consumer (Azevedo and Chasin 2003; Da silva et al. 2006; Euclides and Medeiros 2003; Nicodemo and Laura 2001; Trevizan et al. 2007). Inductively coupled plasma optical emission spectrometry (ICP OES), in comparison to other atomic spectrometric techniques, can be employed for the determination of a relatively large groups of elements in high or low levels of concentration. Specifically for grass, ICP OES was recommended for analyte detection and quantification ( $\mathrm{Li}$ and Thornton 1993; Madejón et al. 2002; Alexander et al. 2006; Farfel et al. 2005; Melo et al. 2009). In this way, $\mathrm{As}, \mathrm{Bi}$ and $\mathrm{Sb}$ were determined, after sample calcination at $450{ }^{\circ} \mathrm{C}$ for $6 \mathrm{~h}$ in the presence of $\mathrm{Mg}\left(\mathrm{NO}_{3}\right)_{2}$, using hydride generation ( $\mathrm{Li}$ and Thornton 1993). Digestion with nitric acid in a microwave oven (Madejón et al. 2002) or in digestion blocks with controlled temperature were used for the determination of $\mathrm{As}, \mathrm{Cd}, \mathrm{Cu}, \mathrm{Ca}, \mathrm{Fe}$,
$\mathrm{K}, \mathrm{Mn}, \mathrm{Mg}, \mathrm{Ni}, \mathrm{Pb}, \mathrm{P}, \mathrm{Tl}$ and $\mathrm{Zn}$ (Alexander et al. 2006; Farfel et al. 2005). Nitric plus perchloric acids in digestion block were used for the determination of As (Melo et al. 2009). The goal of this work is the development of a method for the simultaneous determination of 20 elements in grass from the metropolitan area of Curitiba and Castro, in the State of Paraná, Brazil. The samples will be acid digested in a focused microwave system, prior to the analysis. The principal components analysis (PCA) will used for data interpretation.

\section{MATERIALS AND METHODS}

\section{Instrumentation}

The emission intensity signals, in peak height, were measured in an ICP OES instrument, model Vista Pro from Varian (Mulgrave, Australia), using the experimental conditions shown in Table 1. A focused microwave system, Star System 2 from CEM (Matthews, NC, USA) was employed for sample digestion. A mechanical Mill, model 3600 from Perten (Huddinge, Switzerland) was used to grind the samples previously dried in a drying oven model 400 ND from Nova Ética (Vargem Grande Paulista, SP, Brazil).

Table 1 - Instrumental parameters of the ICP OES.

\begin{tabular}{ll}
\hline Radiofrequency & $40 \mathrm{MHz}$ \\
Forward power & $1.2 \mathrm{~kW}$ \\
Plasma gas flow rate & $15.0 \mathrm{~L} \mathrm{~min}^{-1}$ \\
Auxiliary gas flow rate & $1.5 \mathrm{~L} \mathrm{~min}^{-1}$ \\
Measurement mode & Peak height \\
Replicate read time & $3 \mathrm{~s}$ \\
Instrument stabilization delay & $35 \mathrm{~s}$ \\
Replicates & 3 \\
Torch & Quartz, axial view \\
Nebulizer type & Concentric glass K \\
\hline
\end{tabular}

\section{Reagents and materials}

All chemicals were of analytical grade, unless otherwise specified. High purity water (resistivity of $18.2 \mathrm{M} \Omega \mathrm{cm}$ ) was de-ionized in a Milli-Q system (Bedford, MA, USA). The following reagents were used: $65 \%$ v/v $\mathrm{HNO}_{3}$ Suprapur $^{\circledR}$ (Part $\left.\mathrm{n}^{\circ} 1.00441 .1000\right) ; 30 \% \mathrm{v} / \mathrm{v} \mathrm{H}_{2} \mathrm{O}_{2}$ (Part $\mathrm{n}^{\mathrm{o}}$ $1.07210 .1000)$ and $30 \% \mathrm{v} / \mathrm{v} \mathrm{HCl}$ Suprapur ${ }^{\circledR}$ (Part $\mathrm{n}^{\circ}$ 1.00318.0250), all from Merck (Darmstadt, Germany). Aqua regia $\left(\mathrm{HCl}+\mathrm{HNO}_{3} 3: 1\right.$ molar ratio) and inverse aqua regia $\left(\mathrm{HCl}+\mathrm{HNO}_{3} 1: 3\right.$ molar ratio) were prepared by mixing the concentrated acids. Mono-elemental stock standard solutions containing $1000 \mathrm{mg} \mathrm{L}^{-1}$ of the analytes, from AccuStandard (New Haven, USA) were used to compose the multi-elemental standard solutions used for calibration, in the concentration range from 0.1 to $2 \mathrm{mg} \mathrm{L}^{-1}$ of the analytes in $10 \% \mathrm{v} / \mathrm{v} \mathrm{HNO}_{3}$.

\section{Samples and reference certified materials}

Seventeen samples of fodder grass were collected from April to May, 2010 in pastures in the metropolitan area of Curitiba (Campo Magro, 
Campo Largo and Bateias) and in Castro in the State of Paraná, Brazil. Among the samples, the following varieties were found: Avena strigosa Schreb, Lolium perenne and Cynodon sp and from the brachiaria gender. In the field, about $50 \mathrm{~g}$ of the plant was cut close to the root with an inox knife and kept in a plastic bag. In the lab, the plant samples were washed with de-ionized water and dried at $25 \pm 2^{\circ} \mathrm{C}$ until constant weigh ( $\mathrm{Li}$ and Thornton 1993). The samples were then cut into small pieces, ground in a mechanical mill and stored in plastic bags, under the names G1 to G17, being G1 to G10 from the Curitiba area and G11 to G17 from the Castro area.

The following reference certified materials were analyzed: SRM 1515 (Apple Leaves) from the National Institute of Standards and Technology (NIST, Gaithersburg, MD, USA) and SRM 1573 (Tomato Leaves) from the National Bureau of Standards (NBS, Washington, DC, USA).

\section{Sample preparation}

An aliquot of about $0.5 \mathrm{~g}$ of the ground sample was weighed and transferred to the glass tube of the focused microwave system. Then, $5 \mathrm{~mL}$ of concentrated $\mathrm{HNO}_{3}$ and $4 \mathrm{~mL}$ of concentrated $\mathrm{H}_{2} \mathrm{O}_{2}$ were added to the flask that was left standing for $12 \mathrm{~h}$, before being digested in the focused microwave system under reflux, for $5 \mathrm{~min}$ at
$110{ }^{\circ} \mathrm{C}$. The resulting solution was filtrated through a filter paper from JProlab, (No JP41, Curitiba, Brazil) and transferred to a $50 \mathrm{ml}$ volumetric flask, before completing the volume with water. For comparison purpose, the G1 sample was also digested using $10 \mathrm{~mL}$ of aqua regia or inverse aqua regia.

\section{Statistical program}

The statistical program Statgraphics Plus 5.0 (Statgraphics Graphics Corp.,ST.SC., USA) was used for the principal component analysis (PCA).

\section{RESULTS AND DISCUSSION}

\section{Sample digestion}

Table 2 shows the obtained results for the analytes concentrations in G1 sample using the three mixtures, above mentioned, in the digestion. According to the pared $t$-test, at a $95 \%$ confidence level, the three results for each analyte are in agreement. The method using nitric acid plus hydrogen peroxide was adopted, only because the precision, expressed by the relative standard deviation, was somewhat better than for the other two mixtures. This experiment also indicates that the proposed method is accurate.

Table 2 - Obtained concentrations (average \pm standard deviation) for the sample $\mathrm{G} 1, \mathrm{mg} \mathrm{kg}^{-1}$ (minor and trace elements) and $\mathrm{g} / 100 \mathrm{~g}$ (major elements) in different media, $\mathrm{n}=3$, dry weigh basis.

\begin{tabular}{|c|c|c|c|}
\hline Analyte & $\mathrm{HNO}_{3}+\mathrm{H}_{2} \mathrm{O}_{2}$ & $\mathrm{HCl}+\mathrm{HNO}_{3}(3: 1)$ & $\mathrm{HCl}+\mathrm{HNO}_{3}(1: 3)$ \\
\hline $\mathrm{Al}$ & $16 \pm 1$ & $16 \pm 3$ & $16 \pm 2$ \\
\hline As & $<2$ & $<2$ & $<2$ \\
\hline $\mathrm{Ba}$ & $1.7 \pm 0.1$ & $1.7 \pm 0.2$ & $1.8 \pm 0.2$ \\
\hline $\mathrm{Ca}(\mathrm{g} / 100 \mathrm{~g})$ & $0.36 \pm 0.01$ & $0.36 \pm 0.04$ & $0.36 \pm 0.01$ \\
\hline $\mathrm{Cd}$ & $<0.1$ & $<0.1$ & $<0.1$ \\
\hline Co & $<0.1$ & $<0.1$ & $<0.1$ \\
\hline $\mathrm{Cr}$ & $<0.5$ & $<0.5$ & $<0.5$ \\
\hline $\mathrm{Cu}$ & $10.4 \pm 0.9$ & $9.9 \pm 1.4$ & $9.9 \pm 0.1$ \\
\hline $\mathrm{Fe}$ & $181 \pm 8$ & $183 \pm 7$ & $176 \pm 5$ \\
\hline $\mathrm{K}(\mathrm{g} / 100 \mathrm{~g})$ & $2.61 \pm 0.02$ & $2.64 \pm 0.24$ & $2.70 \pm 0.04$ \\
\hline $\mathrm{Mg}(\mathrm{g} / 100 \mathrm{~g})$ & $0.21 \pm 0.01$ & $0.21 \pm 0.02$ & $0.21 \pm 0.01$ \\
\hline $\mathrm{Mn}$ & $74 \pm 1$ & $73 \pm 1$ & $73 \pm 2$ \\
\hline Mo & $<0.5$ & $<0.5$ & $<0.5$ \\
\hline $\mathrm{Na}(\mathrm{g} / 100 \mathrm{~g})$ & $0.046 \pm 0.004$ & $0.047 \pm 0.004$ & $0.041 \pm 0.001$ \\
\hline $\mathrm{Ni}$ & $<0.5$ & $<0.5$ & $<0.5$ \\
\hline$P(g / 100 g)$ & $0.28 \pm 0.01$ & $0.27 \pm 0.01$ & $0.28 \pm 0.01$ \\
\hline $\mathrm{Pb}$ & $<1$ & $<1$ & $<1$ \\
\hline $\mathrm{Sb}$ & $<1$ & $<1$ & $<1$ \\
\hline $\mathrm{Se}$ & $<3$ & $<3$ & $<3$ \\
\hline $\mathrm{Zn}$ & $38 \pm 2$ & $37 \pm 2$ & $38 \pm 4$ \\
\hline$R S D, \%$ & $0.8-8.7 \%$ & $1.4-18.8 \%$ & $1-13 \%$ \\
\hline
\end{tabular}




\section{Figures of merit}

The figures of merit obtained for sample G1 are shown in Table 3, together with the analytical lines used for the intensity signal measurements. The intensity peaks for the G1 sample, not shown in this paper, were very similar to the intensity peaks for the standard solutions for the different analytes, also indicating absence of interference. Absence of interference was verified also for sample G2, by applying the recovery test and by the analysis of two certified reference materials, as described below. Certainly, the sample digestion and dilution allowed the interference free analysis of grass samples. The linear correlation coefficients of the calibration curves in $10 \% \mathrm{v} / \mathrm{v}$ $\mathrm{HNO}_{3}$ were higher than 0.999 , demonstrating good and adequate linearity. The limit of detection (LOD) and the limit of quantification (LOQ) were defined as the ratios $3 \mathrm{~s} / \mathrm{b}$ and $10 \mathrm{~s} / \mathrm{b}$, respectively, where $\mathrm{s}$ is the standard deviation of 10 measurements of the blank and $b$ is the slope of the calibration curve (Nolte 2003; Miller et al. 2000). The obtained limits, shown in Table 3, demonstrate that the proposed method is adequate for the determination of $\mathrm{Al}, \mathrm{Ba}, \mathrm{Ca}, \mathrm{Cu}, \mathrm{Fe}, \mathrm{K}$, $\mathrm{Mg}, \mathrm{Mn}, \mathrm{Na}, \mathrm{P}$ and $\mathrm{Zn}$ in grass, with $\mathrm{LOQ}$ values going from 0.05 ( $\mathrm{Mg}$ and $\mathrm{Mn}$ ) to $1 \mathrm{mg} \mathrm{kg}^{-1}$ (Al, Fe and $\mathrm{K}$ ). The linear range for all analytes was from the LOQ values up to $200 \mathrm{mg} \mathrm{kg}^{-1}$. However, the proposed method is not enough sensitive for trace elements such as $\mathrm{As}, \mathrm{Cd}, \mathrm{Co}, \mathrm{Cr}, \mathrm{Mo}, \mathrm{Ni}, \mathrm{Pb}, \mathrm{Sb}$ and $\mathrm{Se}$, for which the concentrations were below the LOQ values (from $0.1 \mathrm{mg} \mathrm{kg}^{-1}$ for $\mathrm{Cd}$ to $3 \mathrm{mg}$ $\mathrm{kg}^{-1}$ for $\mathrm{Se}$ ), as it will be shown later, in the analytical application.

Table 3 - Figures of merit: slope of calibration curve, correlation coefficient (R), limit of detection (LOD) and quantification (LOQ) for $0.5 \mathrm{~g}$ of the sample in a final volume of $50 \mathrm{~mL}$. Linear range up to $200 \mathrm{mg} \mathrm{kg}^{-1}$.

\begin{tabular}{|c|c|c|c|c|c|}
\hline Analyte & Lines, $\mathbf{n m}$ & Slope, $\left(\mathrm{kg} \mathrm{mg}^{-1} \mathrm{~s}^{-1}\right)$ & $\mathbf{R}$ & LOD, $\left(\mathrm{mg} \mathrm{kg}^{-1}\right)$ & LOQ, $\left(\mathrm{mg} \mathrm{kg}^{-1}\right)$ \\
\hline $\mathrm{Al}$ & 396.152 & 44500 & 0.99996 & 0.25 & 1 \\
\hline As & 193.696 & 700 & 0.99998 & 0.5 & 2 \\
\hline $\mathrm{Ba}$ & 455.403 & 193000 & 0.99999 & 0.03 & 0.1 \\
\hline $\mathrm{Ca}$ & 422.673 & 125000 & 0.99959 & 0.02 & 0.1 \\
\hline $\mathrm{Cd}$ & 226.502 & 37000 & 0.99999 & 0.02 & 0.1 \\
\hline Co & 230.786 & 14200 & 0.99998 & 0.03 & 0.1 \\
\hline $\mathrm{Cr}$ & 267.716 & 50400 & 0.99991 & 0.10 & 0.5 \\
\hline $\mathrm{Cu}$ & 327.395 & 52600 & 0.99993 & 0.05 & 0.2 \\
\hline $\mathrm{Fe}$ & 238.204 & 40100 & 0.99992 & 0.3 & 1 \\
\hline $\mathrm{K}$ & 769.897 & 28100 & 0.99953 & 0.2 & 1 \\
\hline $\mathrm{Mg}$ & 280.270 & 231000 & 0.99998 & 002 & 0.05 \\
\hline $\mathrm{Mn}$ & 257.610 & 227000 & 0.99998 & 0.02 & 0.05 \\
\hline Mo & 202.032 & 5900 & 0.99997 & 0.12 & 0.5 \\
\hline $\mathrm{Na}$ & 589.592 & 274000 & 0.99987 & 0.2 & 1 \\
\hline $\mathrm{Ni}$ & 231.604 & 5790 & 0.99997 & 0.1 & 0.5 \\
\hline $\mathrm{P}$ & 213.618 & 1260 & 0.99996 & 0.8 & 0.5 \\
\hline $\mathrm{Pb}$ & 220.353 & 2700 & 0.99995 & 0.3 & 1 \\
\hline $\mathrm{Sb}$ & 217.582 & 850 & 0.9999 & 0.3 & 1 \\
\hline $\mathrm{Se}$ & 196.026 & 381 & 0.99999 & 0.8 & 3 \\
\hline $\mathrm{Zn}$ & 213.857 & 34000 & 0.99996 & 0.02 & 0.1 \\
\hline
\end{tabular}

Precision and accuracy were evaluated for the G2 sample, which was enriched with $1 \% \mathrm{~m} / \mathrm{m}$ of $\mathrm{Ca}$, $\mathrm{K}, \mathrm{Mg}, \mathrm{Na}$ and $\mathrm{P}$ and $100 \mathrm{mg} \mathrm{kg}^{-1}$ of the minor components elements. The obtained concentrations are shown in Table 4 . The relative standard deviations (RSD) were below $10 \%$, indicating an adequate precision. The recovery values were from $80 \%$ to $107 \%$, demonstrating a good accuracy (Miller and Miller 2000; Okada et al. 2007;
Rosecrance 2005). The accuracy was further demonstrated by the analysis of botanical certified reference materials and the results are shown in Table 5. The recoveries of the certified values were between $83 \%$ and $119 \%$, confirming the adequate accuracy of the proposed method. The obtained precision in the analysis of the certified materials was also adequate, confirming RSD values lower than $10 \%$. 
Table 4 - Recovery and RSD values for sample G2, enriched with $1 \% \mathrm{~m} / \mathrm{m}$ of $\mathrm{Ca}, \mathrm{K}, \mathrm{Mg}, \mathrm{Na}$ and $\mathrm{P}$ and $100 \mathrm{mg} \mathrm{kg}^{-1}$ of the minor component elements, $n=7$.

\begin{tabular}{ccccc}
\hline Analyte & Sample $(\mathbf{n}=\mathbf{3})$ & Enriched sample (n=7) & Recovery (\%) & RSD, \% \\
\hline $\mathrm{Al}$ & $6.0 \pm 0.1$ & $106 \pm 1$ & 100 & 0.9 \\
$\mathrm{As}$ & $<2$ & $97 \pm 2$ & 97 & 2.1 \\
$\mathrm{Ba}$ & $18.4 \pm 0.4$ & $113 \pm 1$ & 94 & 1.0 \\
$\mathrm{Ca}(\mathrm{g} / 100 \mathrm{~g})$ & $0.58 \pm 0.02$ & $1.56 \pm 0.03$ & 98 & 1.9 \\
$\mathrm{Cd}$ & $<0.1$ & $97.5 \pm 1.2$ & 98 & 1.2 \\
$\mathrm{Co}$ & $<0.1$ & $93.0 \pm 1.3$ & 93 & 1.4 \\
$\mathrm{Cr}$ & $<0.5$ & $96.5 \pm 0.8$ & 97 & 0.8 \\
$\mathrm{Cu}$ & $8.3 \pm 0.3$ & $103.0 \pm 0.6$ & 95 & 6.4 \\
$\mathrm{Fe}$ & $218 \pm 5$ & $298 \pm 19$ & 80 & 1.4 \\
$\mathrm{~K}(\mathrm{~g} / 100 \mathrm{~g})$ & $2.59 \pm 0.02$ & $3.67 \pm 0.05$ & 107 & 1.5 \\
$\mathrm{Mg}(\mathrm{g} / 100 \mathrm{~g})$ & $0.36 \pm 0.01$ & $1.35 \pm 0.02$ & 99 & 1.0 \\
$\mathrm{Mn}$ & $79 \pm 3$ & $168 \pm 3$ & 89 & 0.9 \\
$\mathrm{Mo}$ & $<0.5$ & $96.3 \pm 1.0$ & 96 & 1.2 \\
$\mathrm{Na}(\mathrm{g} / 100 \mathrm{~g})$ & $0.101 \pm 0.001$ & $1.110 \pm 0.010$ & 101 & 1.1 \\
$\mathrm{Ni}$ & $<0.5$ & $94.0 \pm 1.1$ & 94 & 2.2 \\
$\mathrm{P}(\mathrm{g} / 100 \mathrm{~g})$ & $0.33 \pm 0.01$ & $1.33 \pm 0.014$ & 100 & 1.0 \\
$\mathrm{~Pb}$ & $<1$ & $93 \pm 2$ & 93 & 1.9 \\
$\mathrm{Sb}$ & $<1$ & $100 \pm 1$ & 100 & 7.7 \\
$\mathrm{Se}$ & $<3$ & $106 \pm 2$ & 106 & 101 \\
$\mathrm{Zn}$ & 29 & $130 \pm 10$ &
\end{tabular}

Table 5 - Analysis of botanical certified reference materials, $\mathrm{mg} \mathrm{kg}^{-1}$ (minor and trace elements) and g/100g (major elements), $n=3$.

\begin{tabular}{ccccc}
\hline \multirow{2}{*}{ Analytes } & \multicolumn{2}{c}{ SRM 1515 } & \multicolumn{2}{c}{ SRM 1573 } \\
\cline { 2 - 5 } & Certified & Found & Certified & Found \\
\hline $\mathrm{Al}$ & $286 \pm 9$ & $321 \pm 5$ & $(1200)^{\mathrm{a}}$ & $1100 \pm 50$ \\
$\mathrm{As}$ & $0.038 \pm 0.007$ & $<2$ & $0.27 \pm 0.05$ & $<2$ \\
$\mathrm{Ba}$ & $49 \pm 2$ & $48.1 \pm 0.3$ & ---- & $48.9 \pm 0.8$ \\
$\mathrm{Ca}(\mathrm{g} / 100 \mathrm{~g})$ & $1.526 \pm 0.015$ & $1.55 \pm 0.02$ & $3.00 \pm 0.03$ & $2.97 \pm 0.05$ \\
$\mathrm{Cd}$ & $0.013 \pm 0.002$ & $<0.1$ & $(3)^{\mathrm{a}}$ & $3.4 \pm 0.1$ \\
$\mathrm{Co}$ & $(0.09)^{\mathrm{a}}$ & 0.1 & $(0.6)^{\mathrm{a}}$ & 0.5 \\
$\mathrm{Cr}$ & $(0.3)^{\mathrm{a}}$ & $<0.5$ & $4.5 \pm 0.5$ & $3.8 \pm 0.2$ \\
$\mathrm{Cu}$ & $5.64 \pm 0.24$ & $5.5 \pm 0.1$ & $11 \pm 1$ & $9.4 \pm 0.4$ \\
$\mathrm{Fe}$ & $83 \pm 5$ & $81 \pm 6$ & $690 \pm 25$ & $678 \pm 25$ \\
$\mathrm{~K}(\mathrm{~g} / 100 \mathrm{~g})$ & $1.61 \pm 0.02$ & $1.44 \pm 0.05$ & $4.46 \pm 0.03$ & $4.62 \pm 0.05$ \\
$\mathrm{Mg}(\mathrm{g} / 100 \mathrm{~g})$ & $0.271 \pm 0.008$ & $0.26 \pm 0.01$ & $(0.7)^{\mathrm{a}}$ & $0.61 \pm 0.01$ \\
$\mathrm{Mn}$ & $54 \pm 3$ & $50 \pm 1$ & $238 \pm 7$ & $235 \pm 4$ \\
$\mathrm{Mo}$ & $0.094 \pm 0.013$ & $<0.5$ & ---- & $<0.5$ \\
$\mathrm{Na}$ & $24.4 \pm 1.2$ & $29.0 \pm 1.2$ & ---- & $479 \pm 10$ \\
$\mathrm{Ni}$ & $0.91 \pm 0.12$ & $0.94 \pm 0.05$ & ---- & $0.77 \pm 0.07$ \\
$\mathrm{P}(\mathrm{g} / 100 \mathrm{~g})$ & $0.159 \pm 0.011$ & $0.16 \pm 0.01$ & $0.34 \pm 0.02$ & $0.35 \pm 0.01$ \\
$\mathrm{~Pb}$ & $0.470 \pm 0.024$ & $<1$ & $6.3 \pm 0.3$ & $6.9 \pm 0.1$ \\
$\mathrm{Sb}$ & $(0.013)^{\mathrm{a}}$ & $<1$ & ---- & $<1$ \\
$\mathrm{Se}$ & $0.050 \pm 0.009$ & $<3$ & ----- & $64 \pm 4$ \\
$\mathrm{Zn}$ & $12.5 \pm 0.3$ & $12.9 \pm 0.3$ & $62 \pm 6$ & $1.1-9.1 \%$ \\
$R S D, \%$ & & $0.6-7.4 \%$ & & $83-113 \%$ \\
$R$ Recovery, $\%$ & & $89-119 \%$ & & \\
\hline
\end{tabular}




\section{Analytical application}

Table 6 shows the obtained concentrations for the seventeen samples, after digestion using nitric acid and hydrogen peroxide under microwaves. For nine analytes (the non-essential elements $\mathrm{As}, \mathrm{Cd}$, $\mathrm{Cr}, \mathrm{Ni}, \mathrm{Pb}, \mathrm{Sb}, \mathrm{Co}, \mathrm{Mo}$ and $\mathrm{Se}$ ), the concentrations were below the quantification limits that could indicate that they were grown in non-contaminated environments. Usually, contaminants are more concentrated in the roots than in other parts of the plants, indicating poor translocation (Trevizam et al. 2007; Lamego and Vidal 2007).

Table 6 - Obtained concentrations (average \pm standard deviation) for the seventeen samples, after digestion using nitric acid and hydrogen peroxide under microwaves, $\mathrm{n}=3$.

\begin{tabular}{|c|c|c|c|c|c|c|c|c|c|c|c|}
\hline Samples & Al mg kg ${ }^{-1}$ & Ba mg $\mathrm{kg}^{-1}$ & Cag/100g & Cu mg kg ${ }^{-1}$ & Fe mg kg-1 & $\mathrm{Kg} / 100 \mathrm{~g}$ & $M g g / 100 g$ & Mn mg $\mathrm{kg}^{-1}$ & $\mathrm{Nag} / 100 \mathrm{~g}$ & $P g / 100 g$ & Zn mg kg-1 \\
\hline G1 & $16 \pm 1$ & $1.7 \pm 0.1$ & $0.36 \pm 0.01$ & $10.4 \pm 0.9$ & $181 \pm 8$ & $2.61 \pm 0.02$ & $0.21 \pm 0.01$ & $74 \pm 1$ & $0.046 \pm 0.004$ & $0.28 \pm 0.01$ & $38 \pm 2$ \\
\hline G2 & $6.0 \pm 0.1$ & $18.4 \pm 0.4$ & $0.58 \pm 0.02$ & $8.3 \pm 0.3$ & $218 \pm 5$ & $2.59 \pm 0.02$ & $0.36 \pm 0.01$ & $79 \pm 3$ & $0.101 \pm 0.001$ & $0.33 \pm 0.01$ & 29 \\
\hline G3 & $63 \pm 6$ & $8.3 \pm 0.3$ & $0.66 \pm 0.01$ & $7.0 \pm 0.1$ & $149 \pm 8$ & $1.35 \pm 0.01$ & $0.27 \pm 0.01$ & $38 \pm 3$ & $0.013 \pm 0.001$ & $0.37 \pm 0.01$ & $31 \pm 1$ \\
\hline G4 & $26.0 \pm 0.1$ & $3.4 \pm 0.3$ & $0.49 \pm 0.02$ & $7.4 \pm 0.7$ & $111 \pm 11$ & $1.28 \pm 0.03$ & $0.40 \pm 0.01$ & $19.0 \pm 0.1$ & $0.019 \pm 0.001$ & $0.31 \pm 0.01$ & $40 \pm 4$ \\
\hline G5 & $7.0 \pm 0.1$ & $1.0 \pm 0.1$ & $0.50 \pm 0.01$ & $8.5 \pm 0.7$ & $100 \pm 6$ & $0.87 \pm 0.01$ & $0.32 \pm 0.01$ & $72 \pm 1$ & $0.225 \pm 0.002$ & $0.31 \pm 0.01$ & $29 \pm 1$ \\
\hline G6 & $15.0 \pm 0.1$ & $11.4 \pm 0.3$ & $0.52 \pm 0.02$ & $7.4 \pm 0.7$ & $155 \pm 3$ & $1.51 \pm 0.02$ & $0.34 \pm 0.01$ & $31.0 \pm 0.4$ & $0.010 \pm 0.001$ & $0.32 \pm 0.01$ & $28 \pm 1$ \\
\hline$G 7$ & $439 \pm 45$ & $9.4 \pm 0.6$ & $0.44 \pm 0.02$ & $7.4 \pm 0.7$ & $646 \pm 52$ & $3.38 \pm 0.01$ & $0.29 \pm 0.01$ & $140 \pm 9$ & $0.032 \pm 0.002$ & $0.370 \pm 0.011$ & $24 \pm 2$ \\
\hline G8 & $137 \pm 13$ & $41.2 \pm 0.1$ & $0.28 \pm 0.01$ & $6.9 \pm 0.1$ & $456 \pm 22$ & $1.43 \pm 0.07$ & $0.33 \pm 0.01$ & $88 \pm 9$ & $0.011 \pm 0.001$ & $0.16 \pm 0.01$ & $42 \pm 1$ \\
\hline G9 & $274 \pm 26$ & $8.5 \pm 0.2$ & $0.55 \pm 0.01$ & $10.4 \pm 0.7$ & $617 \pm 60$ & $1.01 \pm 0.01$ & $0.40 \pm 0.01$ & $67 \pm 2$ & 0.0017 & $0.310 \pm 0.001$ & $30 \pm 2$ \\
\hline G10 & $30 \pm 1$ & $3.7 \pm 0.1$ & $0.56 \pm 0.01$ & $7.9 \pm 0.1$ & $145 \pm 2$ & $3.72 \pm 0.02$ & $0.260 \pm 0.002$ & $23 \pm 1$ & 0.008 & $0.300 \pm 0.002$ & $28 \pm 1$ \\
\hline G11 & $145 \pm 2$ & $4.2 \pm 0.2$ & $0.55 \pm 0.01$ & $7.9 \pm 0.1$ & $154 \pm 1$ & $2.98 \pm 0.01$ & $0.380 \pm 0.001$ & $51 \pm 1$ & $0.022 \pm 0.001$ & $0.47 \pm 0.02$ & $26 \pm 2$ \\
\hline G12 & $265 \pm 1$ & $14.8 \pm 0.3$ & $0.62 \pm 0.01$ & $6.0 \pm 0.1$ & $203 \pm 1$ & $3.48 \pm 0.04$ & $0.57 \pm 0.01$ & $29.0 \pm 0.3$ & $0.012 \pm 0.001$ & $0.32 \pm 0.01$ & $28 \pm 2$ \\
\hline G13 & $57 \pm 3$ & $2.8 \pm 0.2$ & $0.25 \pm 0.01$ & $3.90 \pm 0.01$ & $91 \pm 1$ & $2.16 \pm 0.02$ & $0.370 \pm 0.001$ & $120 \pm 2$ & $0.0070 \pm 0.0001$ & $0.050 \pm 0.001$ & $17 \pm 1$ \\
\hline G14 & $83 \pm 2$ & $5.0 \pm 0.2$ & $0.34 \pm 0.02$ & $3.9 \pm 0.1$ & $114 \pm 6$ & $1.89 \pm 0.04$ & $0.42 \pm 0.02$ & $158 \pm 4$ & $0.0080 \pm 0.0002$ & $0.060 \pm 0.001$ & $18 \pm 1$ \\
\hline G15 & $61 \pm 4$ & $4.6 \pm 0.1$ & $0.39 \pm 0.01$ & $4.8 \pm 0.3$ & $112 \pm 6$ & $3.22 \pm 0.01$ & $0.43 \pm 0.01$ & $153 \pm 6$ & $0.010 \pm 0.001$ & $0.100 \pm 0.001$ & $23 \pm 1$ \\
\hline G16 & $146 \pm 5$ & $1.80 \pm 0.01$ & $0.26 \pm 0.01$ & $6.9 \pm 0.1$ & $210 \pm 12$ & $1.81 \pm 0.01$ & $0.29 \pm 0.01$ & $88 \pm 5$ & $0.020 \pm 0.001$ & $0.090 \pm 0.002$ & $38 \pm 4$ \\
\hline G17 & $72 \pm 1$ & $7.9 \pm 0.4$ & $0.60 \pm 0.01$ & $6.6 \pm 0.3$ & $77 \pm 3$ & $6.94 \pm 0.21$ & $0.30 \pm 0.01$ & $19.0 \pm 0.1$ & $0.019 \pm 0.001$ & $0.49 \pm 0.01$ & $26 \pm 2$ \\
\hline
\end{tabular}

Eleven elements could be measured: $\mathrm{Al}, \mathrm{Ba}, \mathrm{Ca}$, $\mathrm{Cu}, \mathrm{Fe}, \mathrm{K}, \mathrm{Mg}, \mathrm{Mn}, \mathrm{Na}, \mathrm{P}$ and $\mathrm{Zn}$. Certainly, Ca, $\mathrm{K}, \mathrm{Mg}$ and $\mathrm{P}$ are the most important constituents. The PCA for the concentrations of these analytes is represented in Figure 1, where PC1 is the first principal component and PC2 is the second principal component (Dos Santos et al. 2008; Morgano et al. 1999; Yabe and Oliveira 1998). The $\mathrm{PC} 1$ is related mainly with $\mathrm{Ca}, \mathrm{Cu}$ and $\mathrm{P}$, while the $\mathrm{PC} 2$ is related to $\mathrm{Al}, \mathrm{Fe}$ and $\mathrm{Mn}$. As shown in the Figure, the samples are distributed in three groups. One of them gathers the majority of the samples (G1-G6 and G10-G12), being characterized by relative high concentrations of $\mathrm{Ca}$ and $\mathrm{P}$, which are essential elements for the living being, and of $\mathrm{Cu}$, important for the immunologic system. The samples from this group, except G11 and G12, were grown in the same Curitiba area, what explains its similarity concerning the elemental composition. The second group contains
G7-G9 samples with relatively high concentrations of $\mathrm{Al}, \mathrm{Fe}$ and $\mathrm{Mn}$. They were grown in Campo Magro. The Al concentrations in all samples showed a great variability going from 6 to $439 \mathrm{mg}$ $\mathrm{kg}^{-1}$, indicating differences in acid of the soil (Wenzl et al. 2003). In the third group, involving samples G13-G15, they have a relatively high concentration of $\mathrm{Mn}$, which in conjunction with $\mathrm{P}$ and $\mathrm{Zn}$ activate the animal enzymatic system. The samples of this group come from the Castro area, what could explain their similarity. Two samples, G16 and G17 from the Castro area, do not belong to any of the three groups. Samples G11 and G12 were also collected in Castro, but they were similar to the samples from the Curitiba area. Certainly, the PCA statistical tool can be very useful for understanding the elemental composition of plants, gathering the samples that show similarity in the concentrations of the constituents (Rocha et al. 2000; Schunke 2001). 


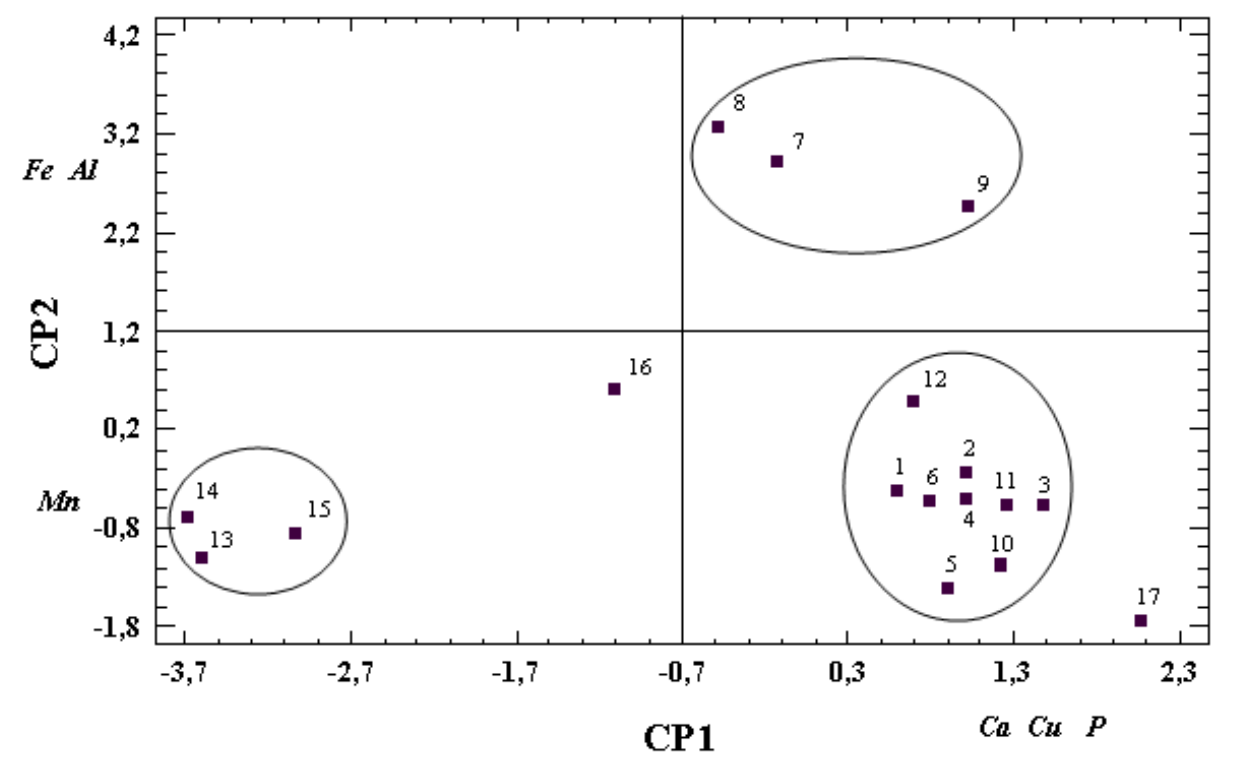

Figure 1 - Principal component analysis applied to the obtained concentrations for the seventeen fodder grass samples from the Curitiba and Castro areas.

\section{CONCLUSIONS}

The simultaneous determination of several elements in grass by ICP OES, following microwave-assisted sample digestion is proposed. Three different acid digestion mixtures produce results in agreement for a grass sample. The precision of the proposed method, measured by the relative standard deviation, is adequate. The method is accurate, as verified by the analysis of certified reference materials, by the recovery test and also by comparing different acid mixtures in the digestion. Eleven out of 20 studied elements could be determined, including the most important ones, concerning nutrition, such as $\mathrm{Ca}, \mathrm{K}, \mathrm{Mg}$ and P. The concentration of 6 non-essential plus 3 trace elements were below their quantification limits. The principal component analysis, applied to the concentration results for 17 grass samples, gather the samples in 3 groups according to their composition. The groups could be associated to different areas of plant culture. Most probably, the proposed method can be used for the analysis of other botanical samples.

\section{ACKNOWLEDGMENTS}

L. M. Baika and A. B. dos Santos have scholarship from Fundação Araucária. A. J. Curtius has a scholarship from Conselho Nacional de Desenvolvimento Científico e Tecnológico.

\section{REFERENCES}

Azevedo SA, Chasin AAM. Metais: Gerenciamento da Toxicidade. São Paulo: Atheneu; 2003.

Alexander PD, Alloway BJ, Dourado AM. Genotypic variations in the accumulation of $\mathrm{Cd}, \mathrm{Cu}, \mathrm{Pb}$ and $\mathrm{Zn}$ exhibited by six commonly grown vegetables. Environ. Pollution 2006; 44:736-745.

Da Silva S, Siqueira JO, Soares CRFS. Mycorrhizal fungi influence on brachiariagrass growth and heavy metal extraction in a contaminated soil. Pesq. agropec. bras., 2006; 41(12): 1749-1757.

Dos Santos JS, Dos Santos ML, Oliveira E. Study of metal and trace element mobilization in aquatic environments of brazilian semi-arid zones applying principal component analysis. Quím. Nova 2008; 31(5): 1107-1111.

Euclides VPB, Medeiros SR. Nutritive value of the prevalente grasses used in Brazil. First ed. Campo Grande: Embrapa Gado de Corte; 2003. 
Farfel MR, Orlova AO, Chaney RL, Lees PSJ, Rohde C, Ashley PJ. Biosolids compost amendment for reducing soil lead hazards: a pilot study of Orgro ${ }^{\circledR}$ amendment and grass seeding in urban yards. The Sci. of the Total Environ. 2005; 340: 81-95.

Li X, Thornton I. Arsenic, antimony and bismuth in soil and pasture herbage in some old metalliferous mining areas in England. Environ. Geog. and Health. 1993; 15(2/3): 135-144.

Lamego FP, Vidal RA. Phytoremediation: plants like agents of despolution? Ecotoxicol. e Meio Amb. 2007; 17: 9-18.

Martuscello JA, Jank L, Gontijo Neto MM, Laura VA, Da Cunha DNFV. Genus Brachiaria grass yields under different shade levels. R. Bras. Zootec. 2009; 38(7): 1183-1190.

Madejón P, Murillo JM, Marañón T, Cabrera F, López $\mathrm{R}$. Bioaccumulation of $\mathrm{As}, \mathrm{Cd}, \mathrm{Cu}, \mathrm{Fe}$ and $\mathrm{Pb}$ in wild grasses affected by the Aznalcóllar mine spill (SW Spain). The Sci. of the Total Environ. 2002; 290: 105120.

Melo RF, Dias LE, Mello JWV, Oliveira JA. Potential of four herbaceous forage species for phytoremediation of a soil contaminated with arsenic. R. Bras. Ci. Solo. 2009; 33: 455-465.

Miller JN, Miller JC. Statistics and Chemometries for Analytical Chemistry. 5th ed. Edinburgh: Pearson Education; 2000.

Morgano MA, Queiroz SCN, Ferreira MMC. Minerals determination in juices by inductively coupled plasma optical emission spectrometry. Ciênc. Tecnol. Aliment. 1999; 19(3): 344-348.

Nicodemo MLF, Laura VA. Minerals in forages: chemical forms, distribution and bioavailability. First ed. Campo Grande: Embrapa Gado de Corte; 2001.

Nolte J. ICP Emission Spectrometry: a practical guide. Owingen: Wiley-VCH; 2003.
Okada IA, Duran MC, Buzzo ML, Dovidauskas S, Sakuma AM, Zenebon O. Validation and application of an analytical method for determining inorganic nutrients in milled rice. Cienc. Tecnol. Aliment. 2007; 27(3): 492-497.

Rocha GP, Evangelista AR, Paiva PCA, Freitas RTF, Garcia E, Rosa B. Mineral composition of three grasses of the Cynodon genus. Ciênc. Anim. Bras. 2000; 1(1): 31-41.

Sousa LF, Maurício RM, Gonçalves LC, Saliba EOS, Moreira GR. Productivity and nutritional value of Brachiaria brizantha $c v$. Marandu in a silvopastoral system. Arq. Bras. Med. Vet. Zootec. 2007; 59(4), 1029-1037.

Schunke RM. Interaction between Pastures Fertilization and Mineral Supplementation of Cattle. First ed. Campo Grande: Embrapa Gado de Corte; 2001.

Rosecrance AE. Quality Assurance. In: Eaton AD, Clesceri LS, Rice EW, Greenberg AE. Standard Methods for the Examination of Water and Wastewater. 21st ed. Maryland: American Public Health Association; 2005. 1-5.

Trevizam AR, Vitti GC, Silva MLS. Concentration of heavy metals in grain of plants cultivated in soil with different contamination levels. Pesquisa Agropec. Bras. 2007; 42(4): 527-535.

Wenzl P, Mancilla LI, Mayer JE, Albert R, Rao IM. Simulating infertile acid soils with nutrient solutions: the effects on Brachiaria species. Soil Sci. Soc. Am. J. 2003; 67: $1457-1469$.

Yabe MJS, Oliveira E. Heavy metals in fresh waters for evaluation of hydrographic basins. Quím. Nova 1998; 21(5): 551-556. 